\title{
A Discussion about American Mathematics Education from an
}

\section{Administrative Perspective}

\author{
Tao Wang ${ }^{1}$ and Miaomiao Yang ${ }^{2}$ \\ ${ }^{1}$ Base Depart, Zhengzhou University of Science \& Technology \\ ${ }^{2}$ Zhengzhou Institute of Technology, Zhengzhou, China
}

\begin{abstract}
In this paper we reflect on the roles and responsibilities of academic leaders in encouraging faculty in mathematics departments to value contributions to mathematics teaching and learning. We discuss how academic leaders can and should use their perspective, position and influence to encourage productive dialogue between practitioners of mathematics and mathematics education; to use assessment of student learning as an opportunity to further this dialogue; and to value and reward work in mathematics teaching and learning in the hiring, evaluation, tenure, promotion, and merit processes.
\end{abstract}

Keywords. Assessment, mathematics education, scholarship of teaching and learning.

\section{Introduction}

Faculty at American colleges and universities are responsible for teaching, research, and service, or what the American Association of University Professors describes as "student-centered work," "disciplinary- or professional-centered work," and "community-centered work" [1]. Academic leaders in today's colleges and universities, especially deans, are responsible for supporting this tri-partite work of the faculty with the overall goal of promoting excellence in their institutions and advancing institutional mission. As such, an academic leader must have a future-oriented perspective; take a wide, cross-campus view; and prioritize the support and nurturing of activities that contribute to the institution's broad and strategic goals .

Here we discuss how academic leaders can use their perspective, position, and influence to encourage and value the work of mathematics faculty in mathematics education. We regard the definition of mathematics education and the associated contributions to be intentionally broad and to encompass work in pedagogy, curricula, and outreach, as well as research in mathematics education. We focus primarily on approaches to supporting the professional-centered work of the mathematician in mathematics education, as this connects more closely with our backgrounds and experiences. We also provide examples to illustrate what academic leaders actually do and what results they achieve. An important note: for convenience, we will often refer to the academic leader as the dean. In reality, the academic leader could be a department chair, a program director, a division head, an associate dean, an associate or vice president for academic affairs, a provost, or even a president. What matters here is that the individual is a respected leader, has some financial discretion and some influence, and possesses a viewpoint that can encompass both local issues and global issues.

We consider the role of academic leaders in facilitating productive interactions and discuss their contributions to this area. We also address the increasing emphasis on assessment of student learning in higher education and the relationship between assessment and disciplinary-centered work. Finally we discuss contributions to the teaching and learning of mathematics in the context of a faculty member's professional and career development, with particular attention to how 
these contributions may be evaluated. Throughout the paper, we highlight the important role of academic leaders in supporting and valuing all forms of contributions to mathematics education.

\section{Mathematics education: as facilitation of productive interactions}

Our fundamental conviction is that practitioners in mathematics and mathematics education have much to learn from one another; in fact, these practitioners could and should be extended to include in-service teachers, education faculty, psychology faculty, and policy makers. We acknowledge the difficulties of past interactions as summarized. But we agree with Ralston and others that cooperation is essential for real progress to be made in $\mathrm{K}-12$ and, therefore, post-secondary mathematics education in America. A significant challenge in this context is that research mathematicians have not always demonstrated an understanding of, or appreciation for, the nature of work in mathematics education. Ball and Forzani addressed this challenge and noted: One impediment is that solving educational problems is not thought to demand special expertise. Despite persistent problems of quality, equity, and scale, many Americans seem to believe that work in education requires common sense more than it does the sort of disciplined knowledge and skill that enable work in other fields. Few people would think they could treat a cancer patient, design a safer automobile, or repair a bridge, for these obviously require special skill and expertise. In mathematics departments, this misunderstanding frequently results in an undervaluing of the work performed by mathematics faculty whose focus has shifted to mathematics education. As Mc Callum diplomatically put it, "Collaborative efforts between mathematicians and mathematics educators are sometimes hampered by a general lack of mutual respect between the two fields". Hyman Bass articulated the challenges further, arguing that there are two common myths regarding research mathematicians becoming involved in mathematics education. Mathematicians promulgate the first myth, sharing “ ... a common belief ... that attention to education is a kind of pasturage for mathematicians in scientific decline." Educators are responsible for the second myth, with doubts about " $\ldots$ the relevance of contributions made by research mathematicians, whose experience and knowledge is so remote from the concerns and realities of school mathematics education". Bass acknowledged that mathematics and mathematics education are not the same, but that "productive interactions" between these fields can exist. Mathematics departments should bear the primary responsibility for supporting these collaborations and "productive interactions." Sometimes, however, they need help in initiating or sustaining these efforts. The silo-like nature of today's higher education makes this a challenge. The prevalent organizational structure in US higher education is one of departments within colleges or schools. This somewhat vertical structure supports discipline-based teaching and research, but isolates departments and inhibits collaboration. As a result, faculty may not see opportunities to work with colleagues in other departments or in other areas of the institution.

\section{Academic leader working on collaborations}

Our experience is that an academic leader who resides outside the department and who has an understanding of the need for cooperation across different areas of the university can bring faculty together around projects that may lead to deeper collaborations. We have seen this at several different institutions. In each of the following examples, an academic leader identified encouraged, or brought together faculty members from across the institution to work on a common project. In several cases, the results went beyond the immediate project to include the deepening of interdisciplinary understandings, the implementation of curricular change, or the advancement of new research partnerships.

(1) Education faculty wanted to develop a graduate degree in education for in-service high school mathematics teachers. Because such a degree needed to have a significant amount of mathematics content (both as a good practice and as a requirement for advanced certification), the input of mathematics faculty was vital. The resulting collaboration led to the development of a joint graduate degree [2]. In a different institution, faculty in the mathematics department sought out a collaboration with faculty in education to design a subject-based master's degree in mathematics education for in- or pre-service teachers. The resulting discussions brought mathematics and education faculty together in new ways, leading to other joint projects that included grant proposals and curriculum development [3]. With support from a federal 
grant, mathematics and education faculty at a 4-year institution and a community college met over the period of a year to compare syllabi for first- and second-year mathematics courses, discuss student success concerns, and review transfer policies. Mathematics and mathematics education faculty served together on a state-wide committee charged with evaluating mathematics placement testing and the role of developmental mathematics in public higher education in that state [4]. A mathematics department chair initiated a collaboration with education faculty and K-12 teachers, supported by National Science Foundation funding, to vertically bridge the school curriculum to research-level mathematics. The innovative partnership benefitted graduate students and faculty at the institution, as well as teachers and students in local K-12 schools, and provided a model for other institutions.

How can deans help? The nature of their role is that they take a cross-institutional perspective. This perspective gives them insights into connections and opportunities, as well as synergies, across a college or university. With this perspective, deans bring together groups of faculty to initiate new programs or build out areas of potential strength. In this context, collaborations that connect mathematics faculty and mathematics education faculty, or that support mathematics faculty with research interests in teaching and learning, should be connected to specific programs (such as the graduate education programs mentioned earlier) or focused to support assessment of student learning (more on that below), student retention goals, or revisions of academic support services. Bennett's chapter in this volume describes work with education faculty who had concerns about a required course for a mathematics education program. The request to replace this course with a "mathematically rigorous capstone course for secondary mathematics teachers that would make explicit connections between college and high school mathematics" [5] gave Bennett the opportunity to not only think carefully about what these students should learn, but to begin a research project in the scholarship of teaching and learning.

Sultan and Artzt presented an example of how faculty from two different departments, with two different worldviews, can collaborate. What began as an initial discussion about the preparation of secondary mathematics teachers led to National Science Foundation funding for a project to recruit high school seniors into a mathematics teacher preparation program. As they noted, "If there is one thing that we have learned it is that collaboration is a complex process. We have to be willing to learn from each other, we have to respect each other, and we have to be willing to change". Holm's chapter in this volume echoes this sentiment. She wrote, "I believe strongly that the mathematical sciences community must maintain the bridges between researchers in mathematics education and practitioners of mathematics education, particularly at the post-secondary level. Moving forward we need to improve our communication and collaboration." [6].

\section{How to build productive interactions}

The call for assessment of student learning in higher education has grown across the United States over the last decade. The use of business terminology in this context, such as "return on investment" and "value-added," is increasingly common at the administrative level and this usage suggests that non-academic models and approaches are being imposed on higher education .Colleges and universities are under tremendous pressure to not only articulate student learning outcomes in general education and in the major, but to assess progress toward these learning outcomes and to demonstrate that this progress is a direct result of the educational experience. These pressures come from federal and state agencies including the United States Department of Education, the media and the public. At the departmental level, regular program reviews may include an expectation for assessment of the curriculum, of student learning, and of other areas such as tutoring and other academic support. While the immediate pressure for assessment and departmental reviews may be external, or from the higher administration, there are potential benefits to a department that engages seriously in this work. The guide-lines prepared by the Mathematical Association of America's Committee on Departmental Reviews frames a self-study as an opportunity for renewal, suggesting that, “...it provides an opportunity for members of a department to move forward together with a shared understanding, a shared set of goals, and a shared commitment".

\section{The role of faculty in the assessment of student learning}


Faculty may rightly argue about the emphasis on assessment in today's higher education world, raising questions about time and effort along with the concern that "the entire premise of 'assessment to improve instruction' - especially if it is offered by outsiders - is that there is something wrong with instruction to begin with" [7]. But when faculty have significant roles in assessment, the results can be meaningful. Discussions about assessment should become conversations about student learning, which then should become transformative conversations about curricula and teaching. As Steen noted in his introduction to Gold et al., "Assessment not only places value on things, but also identifies the things we value". The value of assessment itself is described by Pat Hutchings of the Carnegie Foundation for the Advancement of Teaching, as follows: “... the real promise of assessment—and the area in which faculty involvement matters first and most—lies precisely in the questions that faculty, both individually and collectively, must ask about their students' learning in their regular instructional work: what purposes and goals are most important, whether those goals are met, and how to do better".

Deans should use assessment expectations (or mandates) as opportunities to bring faculty together to have discussions to identify what is valued, to ask questions about students learning within the context of their discipline, and to think deeply about course and curriculum goals .The assessment discussions also present an opportunity for deans to demonstrate to faculty involved in mathematics education that their work is valued. This group not only focused on the student learning outcomes in designing the course, but thought care-fully about the pedagogy and the learning environment. Catepillán's chapter in this volume outlined a different challenge: how to use her background in ethno mathematics to develop a mathematics course that also met the student learning outcomes to qualify as a diversity course. Deans play a role in supporting these discussions and this work in multiple ways.

The most fundamental should be the encouragement, if not the expectation, for broad faculty involvement and leadership in the development and assessment of student learning outcomes. In the context of mathematics, this assessment work presents a very natural opportunity for mathematicians with interests in and experience with mathematics education to take meaningful and significant roles. Deans should provide financial support to begin and sustain these activities. This can take several forms beyond offering stipends or course releases for assessment work; the results often last well beyond the initial activity. We have seen faculty who receive funding to attend conferences and workshops on the assessment of student learning and the scholarship of teaching and learning return energized and excited. This enthusiasm can be infectious, leading to real change in teaching and learning at the institution. In some cases this engagement revitalizes a faculty member's research interests, leading to new work in the scholarship of teaching and learning.

Deans should also lead conversations about recognition and rewards for faculty work in assessment (see below for a broader discussion of this). This can take many forms: providing guidance to hiring committees as they write position descriptions; supporting graduate program directors in the incorporation of assessment into the preparation of graduate students (see Chap. 6 in this volume by Lai et al. for more information about professional development for mathematics graduate teaching assistants); working with faculty to incorporate student self-assessment (in the form of an e-portfolio, for example) into the curriculum ; and leading campus-wide discussions about assessment as scholarship and as part of the departmental and institutional reward system. These discussions may fi t naturally within a larger campus discussion about scholarship .In 1990, Boyer called for a rethinking of how higher education institutions prioritize the "activities of the professoriate". He argued for a new, shared vision of scholarship , one that defines "the work of the faculty in ways that reflect more realistically the full range of academic and civic mandates". These discussions are as "vital" now (in Boyer's terminology) as they were more than 25 years ago.

\section{Faculty professional and career development}

Many faculty (ourselves included) tend to view faculty careers in a traditional progression: first finish graduate school, then perhaps have a post-doctoral position or other short-term experience, then move to a tenure -track position as an assistant professor. From there, the steps are tenure, promotion to associate professor, and then promotion to full professor. (And as we can attest, a move to the administration may be part of a faculty member's academic journey.) Of course there 
are many versions of this progression, and alternate career paths could include an appointment as a full-time lecturer or instructor (perhaps a " professor of the practice ," as the teaching-intensive positions are commonly called), working in industry or in government before taking a position as a faculty member, or laboring as an adjunct at several different institutions. Regardless of the path, an individual faculty member's professional development should never stop. Department chairs and deans should not only recognize this, but should work actively with faculty at all stages of their career to help them reflect on their own professional development and to set short- and long-term goals. Bremser's chapter in this volume provides a compelling reflection of how faculty may naturally change focus and direction as their careers develop. Educated as a research mathematician, Bremser described how she “...began to direct more intellectual energy toward educational issues, with the explicit goal of finding constructive ways to get involved". This led to participation in a workshop on social justice, which in turn led to scholarly engagement in a number of new and unexpected ways.

\section{Conclusion}

The program grew out of an identified need to improve the mathematical and pedagogical content knowledge of local middle school mathematics teachers. The approach meant doing something new: designing an interactive and in-depth experience of mathematics for these teachers using the Math Circle model. As the authors noted, the impact of this work went beyond the audience of middle school teachers. All three authors benefitted from the experience and saw positive impacts on their careers. It also benefitted the department, since the authors brought their reflections about the program back to the department through discussions at department meetings.

\section{References}

1. AAC\&U. (2016). Trends in learning outcomes assessment: Key findings from a survey among administrators at AAC\&U member institutions. Resource document. Association of American Colleges and Universities. Retrieved April 15, 2016.

2. AAUP. (n.d.). What do faculty do? Resource document. Retrieved March 30, 2016.

3. Ball, D., \& Forzani, F. (2007). What makes education research “educational”? Educational Researcher, $36,529-540$.

4. Bass, H. (2005). Mathematics, mathematicians, and mathematics education. Bulletin of the American Mathematical Society, 42 (4), 417-430.

5. Boyer, E. (1990). Scholarship reconsidered: Priorities of the professoriate. San Francisco, CA: Carnegie Foundation for the Advancement of Teaching. Jossey-Bass.

6. Gold, B., Keith, S., \& Marion, W. (Eds.). (1999). Assessment practices in undergraduate mathematics. Washington, DC: The Mathematical Association of America.

7. Hutchings, P. (2010). Opening doors to faculty involvement in assessment. National Institute for Learning Outcomes Assessment. Occasional Paper \#4. Retrieved March 30, 2016. 